\title{
Dimethyl ether (DME) spray characteristics in a common-rail fuel injection system
}

\author{
J Yu and C Bae* \\ Department of Mechanical Engineering, Korea Advanced Institute of Science and Technology (KAIST), Daejon, \\ South Korea
}

\begin{abstract}
The fundamental spray characteristics of dimethyl ether (DME) and conventional diesel were investigated in a constant-volume vessel pressurized by nitrogen gas. A common-rail fuel injection system was adopted with a sac-type injector. DME and diesel were injected into the chamber at two different chamber pressures (atmospheric and $3 \mathrm{MPa}$ ) and three different injection pressures (25, 40 and $55 \mathrm{MPa}$ ) under room temperature condition. A charge coupled device (CCD) camera was employed to capture time series of spray images, so that spray cone angles and penetrations of the DME spray were characterized and compared with those of diesel. For evaluation of the evaporation characteristics, shadowgraphy of the DME spray using an Ar ion laser and an intensified charge coupled device (ICCD) camera was adopted, in conjunction with the Mie scattering imaging technique for single-hole spray. Intermittent hesitating DME spray was observed, depending on the injection conditions, and might be due to the unstable force balance inside the common-rail nozzle during the injection period. The macroscopic spray characteristics of the DME in the atmospheric chamber conditions proved to be intrinsic physical properties of the DME, and they became diesel-like under $3 \mathrm{MPa}$ ambient pressure. A higher injection pressure produced a wider vapour phase area while it decreased with higher chamber pressure conditions.
\end{abstract}

Keywords: dimethyl ether, diesel, common rail, spray characteristics

\section{NOTATION}

$C_{\mathrm{v}} \quad$ coefficient of contraction

$d_{\mathrm{o}} \quad$ nozzle hole diameter

SOE start of energizing injector solenoid

$S \quad$ spray tip penetration

$t \quad$ time elapsed

$t_{\mathrm{b}} \quad$ break-up time

$T_{\mathrm{g}} \quad$ ambient gas temperature

$\triangle P \quad$ pressure drop across the nozzle

$\theta \quad$ half-angle of the spray cone

$\rho_{\mathrm{a}} \quad$ ambient gas density

$\rho_{1} \quad$ liquid density

\section{INTRODUCTION}

Emission substances generated from a compression ignition engine, mainly particulate matter (PM) and

The MS was received on 15 November 2002 and was accepted after revision for publication on 27 August 2003.

* Corresponding author: Department of Mechanical Engineering, KAIST 373-1, Kusong-Dong, Yusong-Gu, Daejon, South Korea. email: csbae@kaist.ac.kr

D14502 O IMechE 2003 nitric oxide and nitrogen dioxide $\left(\mathrm{NO}_{x}\right)$ present serious environmental problems, and additionally carbon dioxide $\left(\mathrm{CO}_{2}\right)$ is being increasingly targeted according to tightening emission requirements. The difficulties in simultaneously reducing the emission levels of both soot and $\mathrm{NO}_{x}$ have resulted in the introduction of dimethyl ether (DME), which is seen as a potential alternative fuel on account of its having no carbon-carbon bond and its oxygen content [1-3]. DME has been adopted as an additive for ignition improvement in alcoholic fuel owing to its excellent autoignition characteristics, and as a result many attempts have now been made to utilize it in diesel engines. The main advantages of DME compared with diesel are a similar order of the cetane number, extremely low PM emissions on account of the high oxygen content ( 34.8 per cent) and the low noise level resulting from the short ignition delay during engine operation [3-6]. However, since it is in a gaseous phase at room temperature and pressure conditions on account of its high vapour pressure, it requires a pressurizing system for the fuel supply. More compression pump work is needed for DME by comparison with diesel because of its higher compressibility [3, 7]. Adoption of an additive for viscosity enhancement is also necessary as the fuel injection system may be 
damaged owing to the extremely low viscosity of DME. These drawbacks of DME have been resolved by employing a common-rail injection system and introducing additives for viscosity enhancement $[2,8,9]$. It has also been suggested that further modification (a longer injection duration or bigger nozzle hole size) of the injection system may be required to compensate for the lower heating value of DME [10]. Carbon monoxide $(\mathrm{CO})$ and unburned hydrocarbon (UHC) emission characteristics in compression ignition engines operated with DME have been recorded as lower than those from diesel fuel, while the effect of DME on $\mathrm{NO}_{x}$ emissions has not been identified yet $[\mathbf{2}, \mathbf{7}, \mathbf{1 1}]$. The exhaust gas recirculation (EGR) method has therefore been recognized as an effective way to minimize $\mathrm{NO}_{x}$ in DME-operated compression ignition engines [2].

Most research on DME has focused on either the engine performance or the emissions in DME-fuelled engines but not the spray itself, even if fundamental spray characteristics are strongly linked with them. One of the main characteristics of DME injection is a highly evaporating spray, resulting in atomization enhancement and rapid fuel and air mixing. It is therefore of importance to understand the fundamental non-evaporating and evaporating spray characteristics of DME. The aims of this study are to investigate and understand the spray characteristics of DME and to compare them with those of diesel in pressurized conditions.

\section{EXPERIMENTAL SET-UP}

\subsection{Fue? injection system}

The fuel injection system employed in this study is a common-rail type and comprises an air-driven fuel pump (MS 188, 69 MPa, Haskel Limited), an accumulator and a back-pressure regulator (69 MPa, Tescom Limited), as shown in Fig. 1. The DME fuel was pressurized to $1.5 \mathrm{MPa}$ by nitrogen gas in a storage vessel to keep it in liquid phase before compressing it inside the pump. The back-pressure regulator maintained the pressure of the accumulator (literally the same as the injection pressure) at a preset value. An identical fuel supply line was used for diesel fuel injection. A five-hole sac type commercial common-rail injector (hole diameter $0.168 \mathrm{~mm}$ ) was adopted and activated with a purpose-built injector driver (TDA $3000 \mathrm{H}$, TEMS Limited), and the fuels were injected at a rate of $2.5 \mathrm{~Hz}$ throughout the study. A lubricity enhancer (Infineum R655) was added to the neat DME in a quantity of $500 \mathrm{ppm}$ in order to minimize any damage to the fuel injection system. The injection rate was measured using the so-called Bosch tube method, which is in principle based on the hydraulic pulse theorem [12].

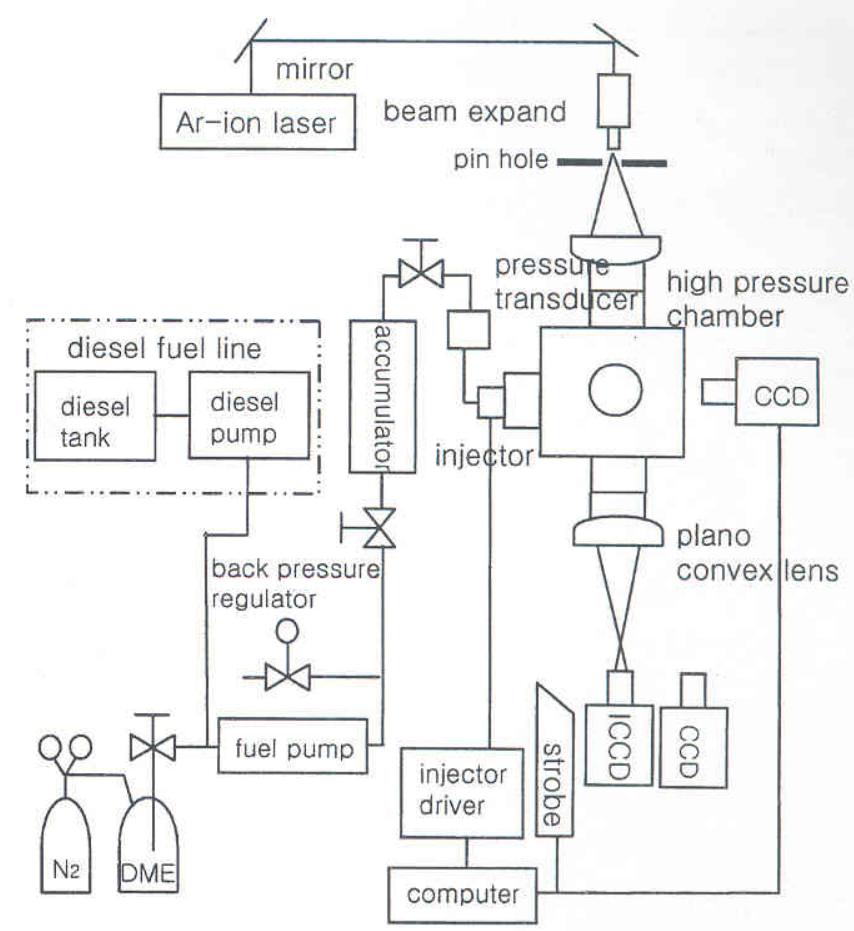

Fig. 1 Experimental set-up

\subsection{Spray visualization system}

DME and diesel were injected into a constant-volume vessel having three windows to allow optical access at room temperature condition, while nitrogen gas was supplied to pressurize the chamber up to $7 \mathrm{MPa}$. Macroscopic spray images were at first taken by the Mie scattering technique, adopting a charge coupled device (CCD) camera (PCO Sensicam) coupled with a strobe light system. A microscopic imaging technique using an intensified charge coupled device (ICCD) camera (Stanford, 4Quick 05A) with nano light illumination, allowing an imaging area of $2.1 \mathrm{~mm} \times 1.7 \mathrm{~mm}$, was also employed under limited conditions for comparative discussion of the macroscopic spray characteristics. To acquire Mie scattered spray images, the injector was placed horizontally in the chamber and the CCD camera was oriented towards the nozzle tip along with positioning of the strobe light at right angles to the camera. For microscopic spray imaging, a nozzle holder was purpose built and placed on the nozzle tip to allow fuel to be injected into the chamber from only one of the five nozzle holes, while the fuel discharged from the other four holes was drained through the drain ports. The CCD camera was placed at the strobe light location used in the macroscopic imaging, and then the nano light was sighted through the test section. To investigate the evaporation characteristics of DME, a shadowgraphic technique adopting an Ar ion laser as a light source was employed with the nozzle holder. The laser beam from the Ar ion laser system was expanded by a microscope objective lens and passed through a $50 \mu \mathrm{m}$ diameter 
pinhole and converged using a planoconvex lens ( $1000 \mathrm{~mm}$ of focal length). After passing through the two optical windows of the chamber, the beam catching the shadowgraphic spray image was refocused by a $300 \mathrm{~mm}$ focal length of another planoconvex lens. The divergent beam then passed into the ICCD camera. To separate the liquid phase of the DME spray from vapour phase in the image, a single-hole Mie scattered image was also acquired; the ICCD camera was replaced with the CCD camera and the strobe was placed at right angles to the camera. The cameras were synchronized with the lighting systems using common-rail injector signals.

\section{SPRAY TIP PENETRATION MODEL}

Many spray tip penetration models have been proposed and evaluated. Hiroyasu and Arai [13] applied the twozone theory that spray comprises a liquid jet and a gas jet. For the period from injection start to liquid break-up, a disintegrating process from liquid column to fine spray was developed along the liquid column so that the spray tip penetration, $S$, can be written as a function of the pressure drop across the nozzle, $\Delta P$, the liquid density, $\rho_{1}$, and the time elapsed, $t$

$$
0<t<t_{\mathrm{b}}, \quad S=0.39\left(\frac{2 \Delta P}{\rho_{1}}\right)^{0.5} t
$$

where the break-up time $t_{\mathrm{b}}=28.65\left(\rho_{1} d_{\mathrm{o}}\right) /\left[\left(\rho_{\mathrm{a}} \Delta P\right)^{0.5}\right], d_{\mathrm{o}}$ is the nozzle hole diameter and $\rho_{\mathrm{a}}$ is the ambient gas density.

After the liquid break-up, the spray tip penetration was modelled by

$$
t_{\mathrm{b}}<t, \quad S=2.95\left(\frac{\Delta P}{\rho_{\mathrm{a}}}\right)^{0.25}\left(d_{\mathrm{o}} t\right)^{0.5}
$$

For limited geometry and injection condition, Dent [14] suggested a model with jet mixing theory considering the ambient temperature effect

$$
S=3.07\left(\frac{295}{T_{\mathrm{g}}}\right)^{0.5}\left(\frac{\Delta P}{\rho_{\mathrm{a}}}\right)^{0.25}\left(d_{\mathrm{o}} t\right)^{0.5}
$$

where $T_{\mathrm{g}}$ is the ambient gas temperature.

Wakuri et al. [15] proposed a spray model based on the momentum theory that air entrained into fuel produces mixed gas together with fuel droplets for the density ratio range $40-60$

$$
S=\left(2 C_{\mathrm{v}}\right)^{0.25}\left(\frac{\Delta P}{\rho_{\mathrm{a}}}\right)^{0.25}\left(\frac{d_{\mathrm{o}} t}{\tan \theta}\right)^{0.5}
$$

where $C_{\mathrm{v}}$ is the coefficient of contraction and $\theta$ is the half-angle of the spray cone.

Schihl et al. [16] and Siebers and Naber [17] also suggested spray tip penetration models, but the basic form of their models was within the framework of con- ventional models

$$
s=f\left[\left(\frac{\Delta P}{\rho_{\mathrm{a}}}\right)^{0.25}, t^{0.5}, \theta, \text { etc. }\right]
$$

In the present study, Dent's model was chosen for comparison with DME spray data.

\section{RESULTS AND DISCUSSION}

DME and diesel at three different injection pressures $(25,40$ and $55 \mathrm{MPa})$ were injected into the chamber at atmospheric and $3 \mathrm{MPa}$ chamber pressures under room temperature conditions. Ten spray images were acquired for each injection event so that repeatability from injection to injection was evaluated in terms of spray tip penetration prior to spray image processing. It was confirmed that repeatability from injection to injection was within 10 per cent in terms of spray tip penetration. The start of injection (SOI) was determined as the first appearance of liquid phase fuel in the images at each case.

\subsection{Line pressure history}

Figure 2 presents the pressure-time history of the DME and diesel in a fuel injection line during the injection period at a preset injection pressure of $55 \mathrm{MPa}$. The pressure history was detected in the fuel line between the accumulator and the injector using a piezoresistancetype pressure transducer (4067A 2000, range 0 $200 \mathrm{MPa}$, Kistler Limited). After an injection event, the duration of the pressure oscillation for the DME was longer than that of the diesel, and its amplitude was lower owing to the high compressibility of DME, as similar trends were reported with in-line pump systems $[8,18]$. In the preliminary experiments, pressure fluctuation was evaluated during the period of ready-state injection at injection pressures preset by the back-pressure regulator, and it was found that the fluctuations for the DME and diesel were within \pm 0.18 and $\pm 0.05 \mathrm{MPa}$, respectively.

\subsection{Spray development}

To activate the common-rail injector employed in the study, 20 A of high current had to be supplied to a solenoid valve in the injector with a certain dwell time (high current holding time), and then down to $10 \mathrm{~A}$ throughout the injection duration. As shown in Fig. 3, the high current holding time determined whether DME became intermittent hesitating spray or atomized in continuous spray development (at least on the macroscopic level). Intermittent hesitating DME spray could also be observed in terms of spray tip penetration, as shown in Fig. 4. Under 25 and $40 \mathrm{MPa}$ injection pressure

Proc. Instn Mech. Engrs Vol. 217 Part D: J. Automobile Engineerin 

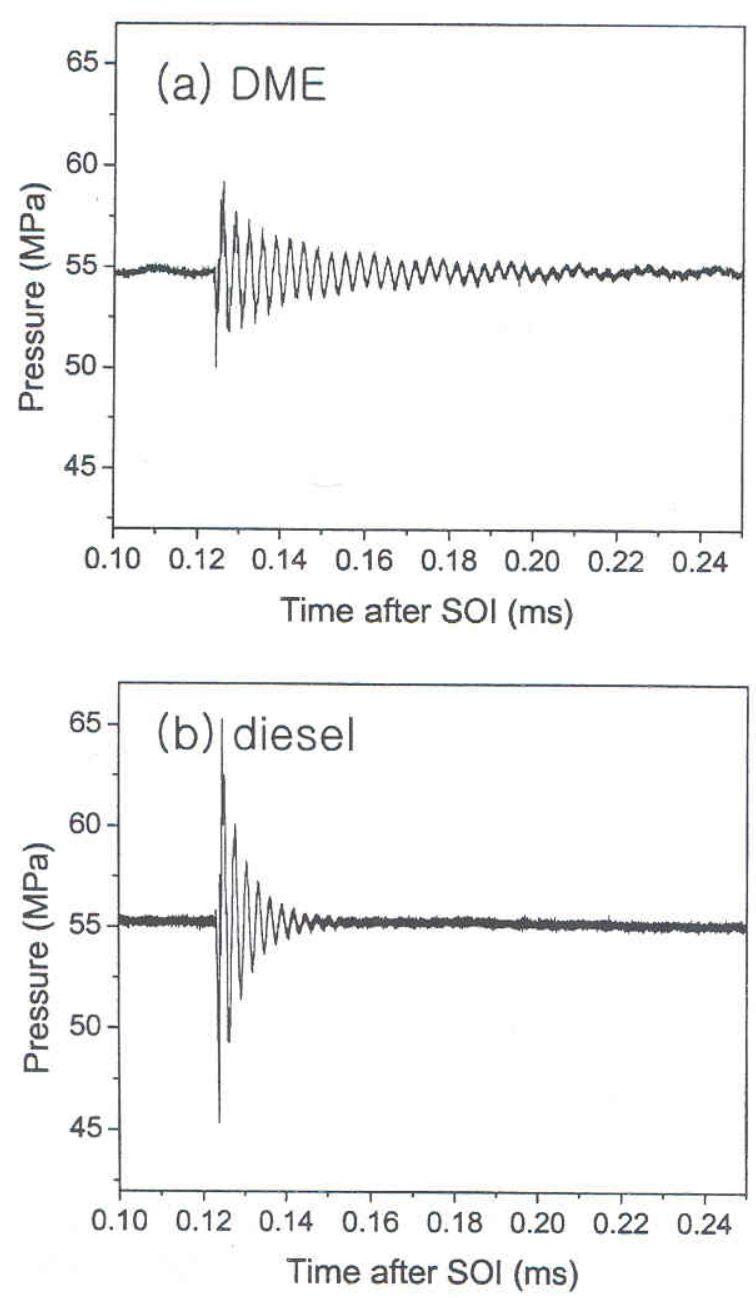

Fig. 2 Pressure-time history at an injection pressure of $55 \mathrm{MPa}$
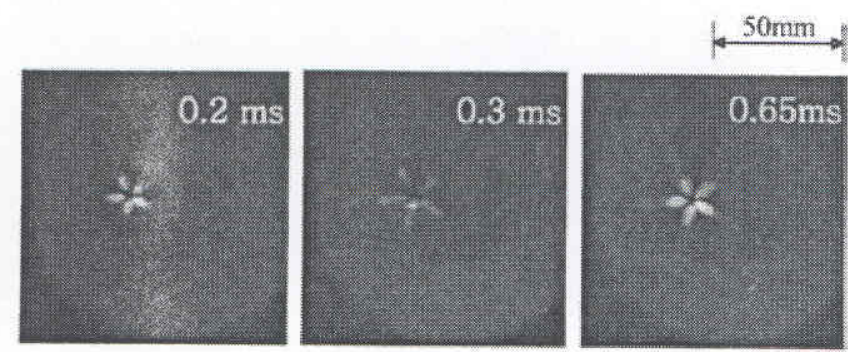

(a) 2004s of high current holding time
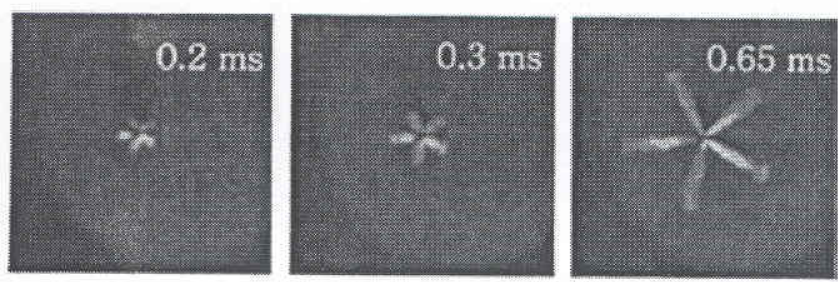

(b) $400 \mathrm{ks}$ of high current holding time

Fig. 3 Effect of injector energizing time on DME spray

Proc. Instn Mech. Engrs Vol. 217 Part D: J. Automobile Engineering

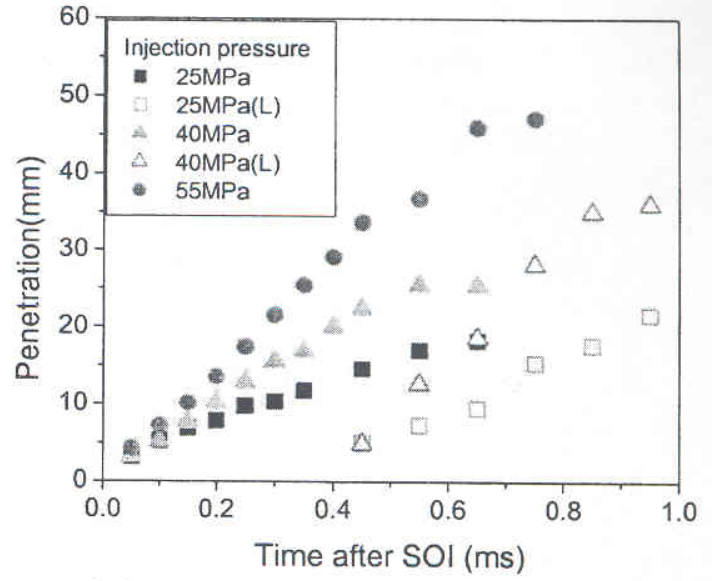

(a) $200 \mu$ s high current holding time

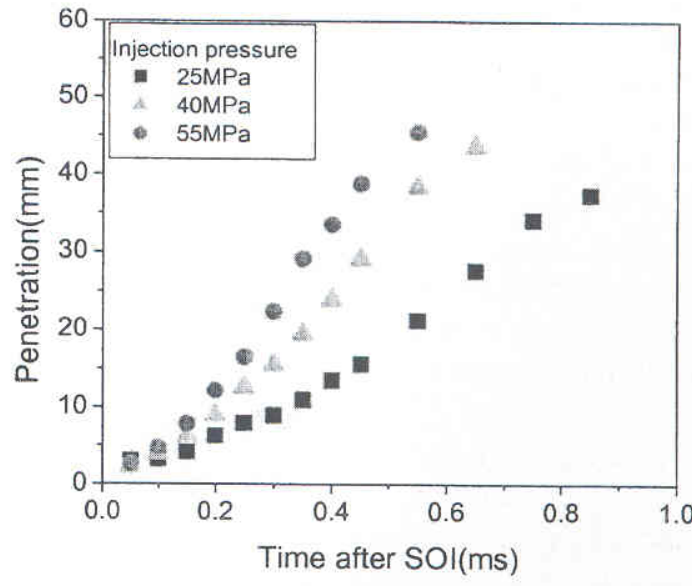

(b) $400 \mu$ s high current holding time

Fig. 4 DME spray tip penetration with different injection pressures at atmospheric chamber pressure

conditions, DME spray discharged with a $200 \mu$ s high current holding time hesitated and was reinjected, while this phenomenon was not observed with a $400 \mu$ s high current dwell time. Two possible reasons could be supposed. The first possible reason might be deteriorated throttling of the nozzle because of the high compressibility of the DME; Egnell [19] investigated the pressure drop between the common rail and nozzle sac and found that for DME injection the pressure drop was higher than that for diesel, resulting in throttling inside the nozzle. The throttling generated during the early stages of DME injection at 25 and $40 \mathrm{MPa}$ pressures might lead to the hesitation and intermittent injection behaviour. Another possibility is an unstable force balance around the ball valve inside the common-rail injector (Fig. 5); movement of the ball valve and the diameters of the bleed and feed orifices have a dominant effect on the flowrate of the injector during the solenoid valve energizing period, and initially decrease in the case of diesel fuel. During the injection period, forces acting on the ball valve were balanced by a magnetic force 


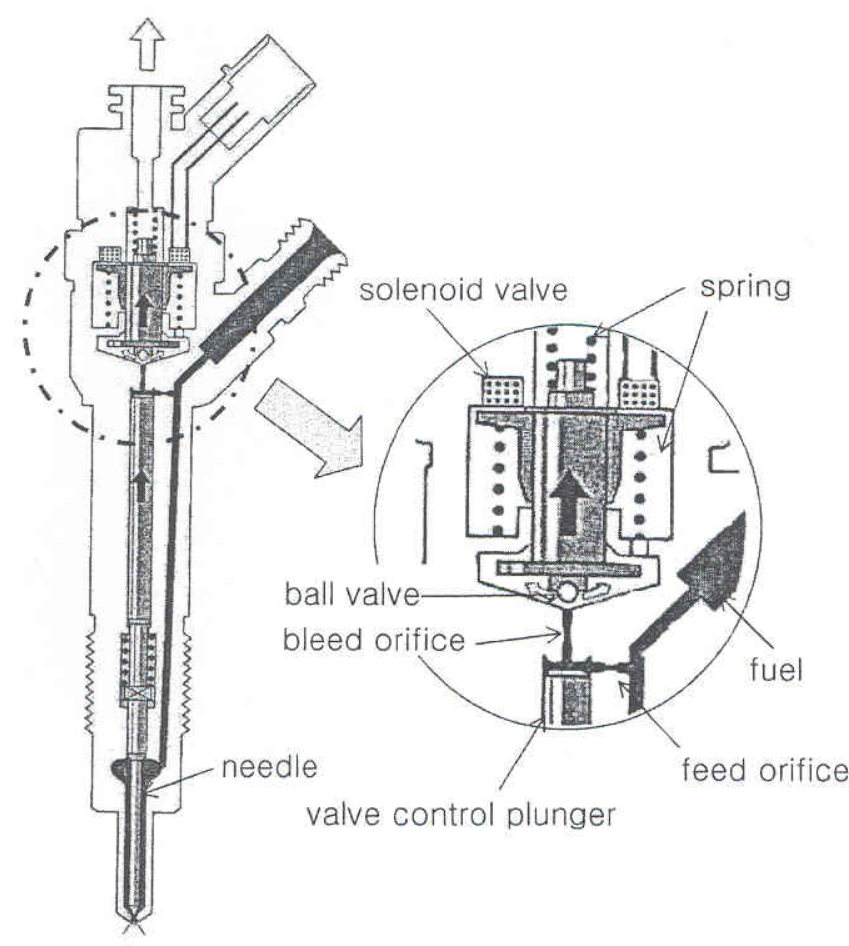

Fig. 5 Schematic of common-rail injector [20]

(proportional to the solenoid energizing time), a spring force (generated from the springs), a damping force (representing the physical properties-compressibility and modulus of elasticity - of the fuel) and a pressure force (from the injection pressure). In this study, decrease in the injection pressure and high current holding time might have caused alternation of the damping and magnetic forces and therefore might have affected the force balance, possibly coupled with cavitation inside the fuel passage. Hence, an intermittent hesitating DME spray might be generated under certain conditions. Similar intermittent hesitating spray from a valve covered orifice (VCO) single-hole injector was previously reported, which was attributed to temporary unbalanced pressure followed by nozzle hole blockage by the needle inside the injector [21]. Further detailed investigation will be carried out in the future on this matter. Throughout the subsequent study, $400 \mu$ s of high current holding time was applied to eliminate ambiguity of the intermittent hesitating spray.

Figure 6 shows the microscopic spray development near the nozzle tip taken with the single-hole microscopic spray acquiring system at $55 \mathrm{MPa}$ injection pressure and atmospheric chamber pressure condition, and the corresponding diesel spray is shown in Fig. 7. DME vapour appeared prior to a gushing liquid phase, as shown in Fig. 6a. On being exposed to atmospheric pressure, the DME rapidly spread in both the longitudinal and the axial directions, breaking up into small droplets and being evaporated, while in the diesel spray a rather narrow edge of the spray boundary appeared and the break-up time seemed to be longer (Figs $6 \mathrm{~b}$ and c com-

D14502 @ IMechE 2003
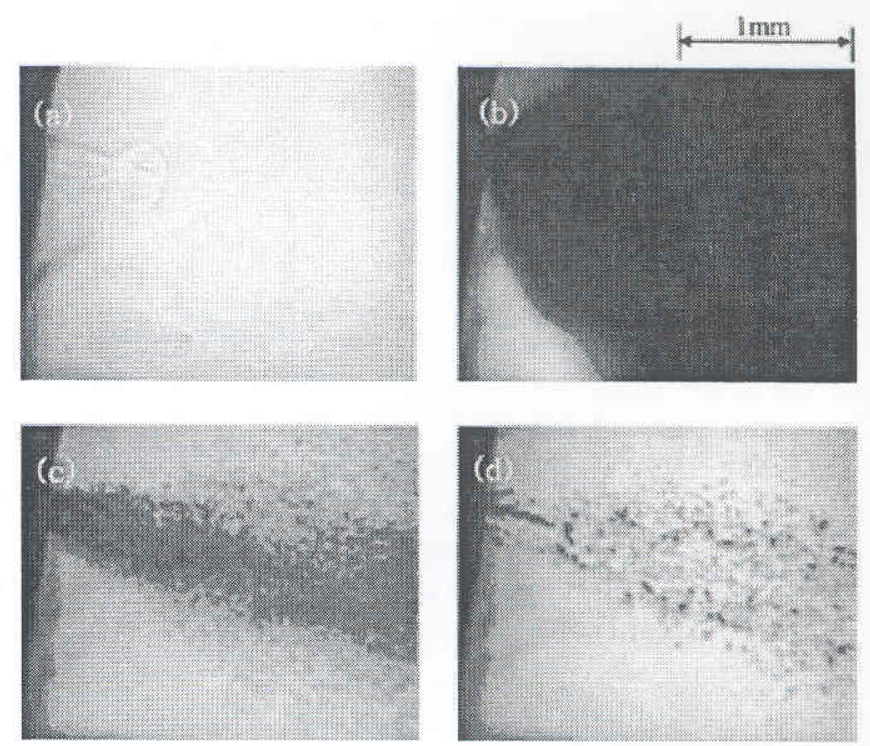

Fig. 6 Microscopic DME spray near the nozzle tip at atmospheric chamber pressure and $55 \mathrm{MPa}$ injection pressure: (a) $0.03 \mathrm{~ms}$ before SOI; (b) $0.1 \mathrm{~ms}$ after SOI; (c) $0.5 \mathrm{~ms}$ after SOI; (d) $0.7 \mathrm{~ms}$ after SOI
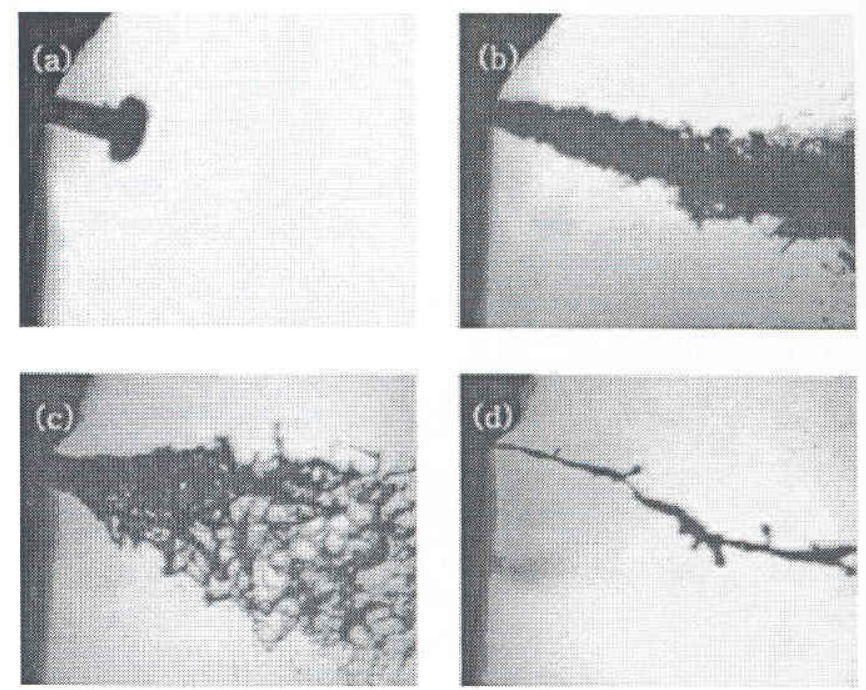

Fig. 7 Microscopic diesel spray near the nozzle tip at atmospheric chamber pressure and $55 \mathrm{MPa}$ injection pressure: (a) $0.03 \mathrm{~ms}$ after SOI; (b) $0.1 \mathrm{~ms}$ after SOI; (c) $0.5 \mathrm{~ms}$ after SOI; (d) $0.7 \mathrm{~ms}$ after SOI

pared with Figs $7 b$ and $c$ ). In the later stages of spray development, the behaviour of draining off the diesel was quite different from that of DME; the diesel had the structure of a long liquid column with several branches (Fig. 7d), while atomized small droplets appeared in the DME and then evaporated, as shown in Fig. 6d. At elevated chamber pressures, there were many difficulties in obtaining microscopic images of the diesel and DME. Although not shown in this paper, the general microscopic diesel spray near the nozzle tip was similar to that of the atmospheric pressure conditions. However, the

Proc. Instn Mech. Engrs Vol. 217 Part D: J. Automobile Engineering 
microscopic DME spray near the nozzle tip seemed to contain finer droplets.

\subsection{Spray tip penetration}

Figure 8 illustrates the spray penetration of the DME and diesel at $55 \mathrm{MPa}$ injection pressure and $3 \mathrm{MPa}$ chamber pressure. As can be seen in Fig. 8, the spray tip penetration was similar to that of diesel as the macroscopic behaviour of the DME above saturation vapour pressure might become liquid like. This may be observed in microscopic spray images of diesel and DME, as shown in Fig. 9. The microscopic images of DME and diesel were obtained at a location $20 \mathrm{~mm}$ along the axial centre-line of the spray at different injection and chamber pressure conditions. As can be seen in Figs 9a and $b$, for the case of atmospheric chamber condition and $25 \mathrm{MPa}$ injection pressure, break-up of the diesel spray was still not completed, and therefore large aggregated diesel lumps appeared (Fig. 9b), while the DME spray had already broken up in small droplets (Fig. 9a). On the other hand, at $3 \mathrm{MPa}$ chamber pressure and
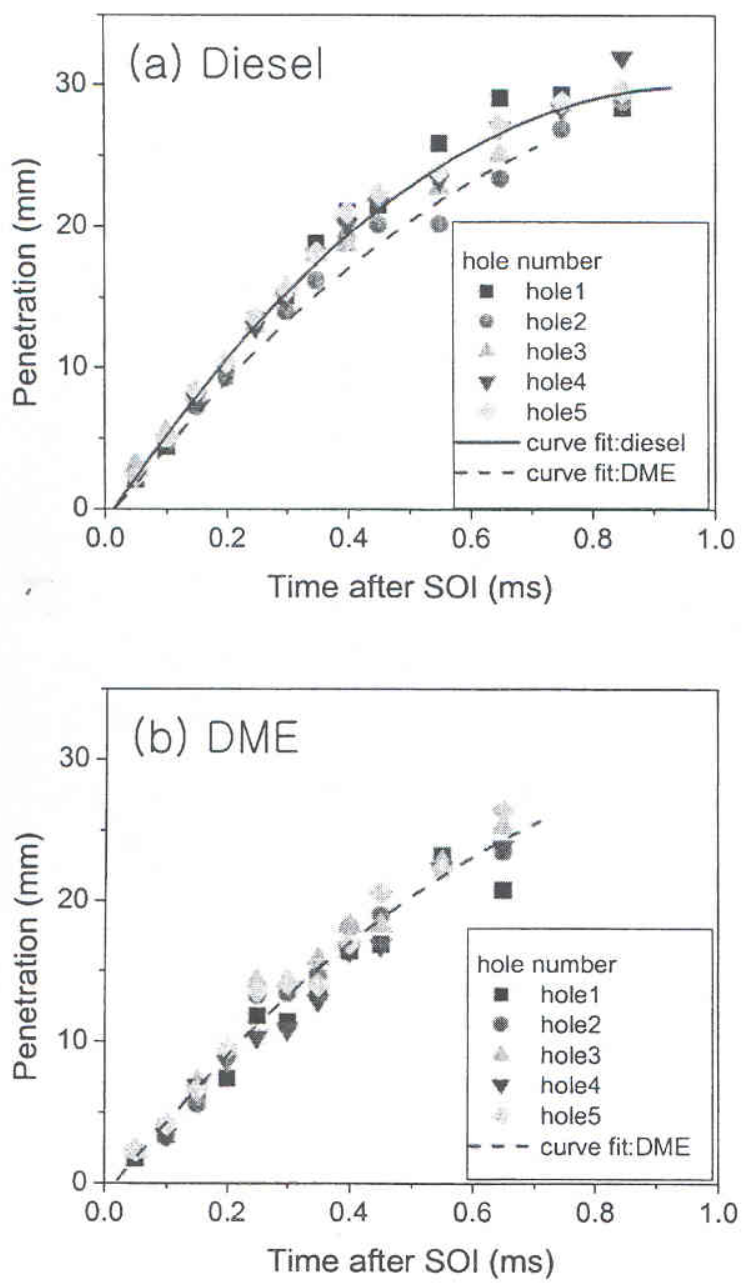

Fig. 8 Spray tip penetration of DME and diesel at $55 \mathrm{MPa}$ injection pressure and $3 \mathrm{MPa}$ chamber pressure
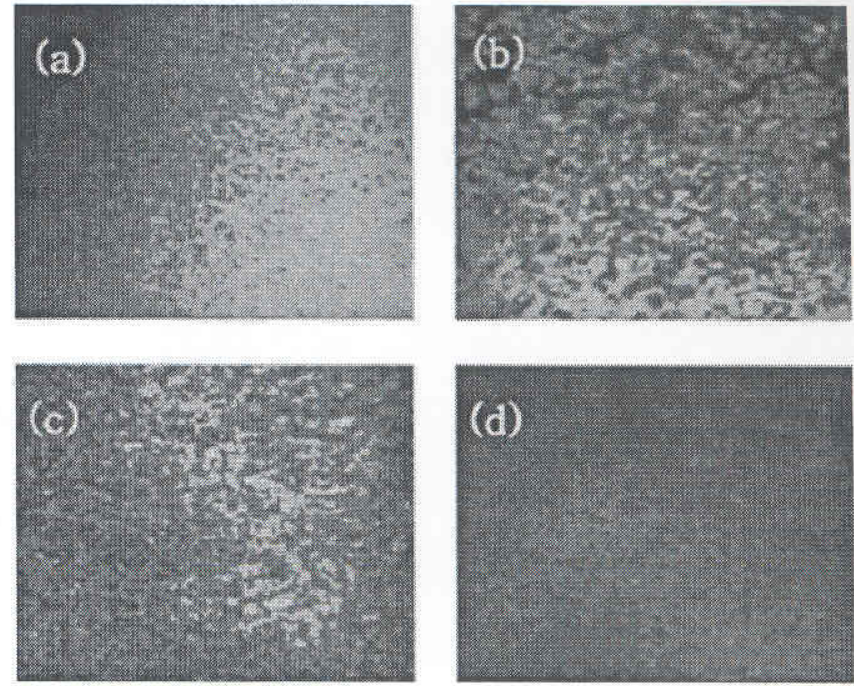

Fig. 9 Microscopic DME and diesel spray images at $20 \mathrm{~mm}$ along the spray centre-line: (a) DME, $0.7 \mathrm{~ms}$ after SOI at $25 \mathrm{MPa}$ injection pressure, atmospheric chamber pressure; (b) diesel, $0.8 \mathrm{~ms}$ after SOI at $25 \mathrm{MPa}$ injection pressure, atmospheric chamber pressure; (c) DME, $0.9 \mathrm{~ms}$ after SOI at $55 \mathrm{MPa}$ injection pressure, $3 \mathrm{MPa}$ chamber pressure; (d) diesel, $0.8 \mathrm{~ms}$ after SOI at $55 \mathrm{MPa}$ injection pressure, $3 \mathrm{MPa}$ chamber pressure

$55 \mathrm{MPa}$ injection pressure (Figs 9c and d), the two spray droplet sizes seemed to be similar, but the diesel spray was more dense in the spray cone volume. The effect of injection pressure on DME spray tip penetration is shown in Fig. 10; the results present spray tip penetrations averaged by taking the mean value of penetrations from the five nozzle holes. As the injection pressure increased, regardless of the chamber pressure, the spray tip penetrations became greater. The spray tip penetration was shortened with a higher chamber pressure. In the present work, the effect of chamber and injection pressures on DME spray tip penetration was consistent with the trend of well-known diesel macroscopic spray characteristics $[22,23]$.

Figure 11 shows the DME injection rate measured by a purpose-built injection rate meter following the Bosch method [12]. It shows the effect of fuel supply pressure on the injection rate under $3 \mathrm{MPa}$ pressure condition. The DME injection rate was described as the fuel flowrate from a nozzle hole. The fuel injection rate shows a triangular shape in the time domain, which represents the elapsed time after the injector solenoid is energized (SOE). The transient characteristics of the fuel injection rate imply that the steady or quasi-steady spray models may not be able to estimate the spray development, especially the penetration. The pressure drop across the nozzle, $\Delta P$, should change rapidly while the injection rate is increasing at the initial spray development phase from a common-rail system. The spray penetration models reviewed in section 3 have been verified with the 


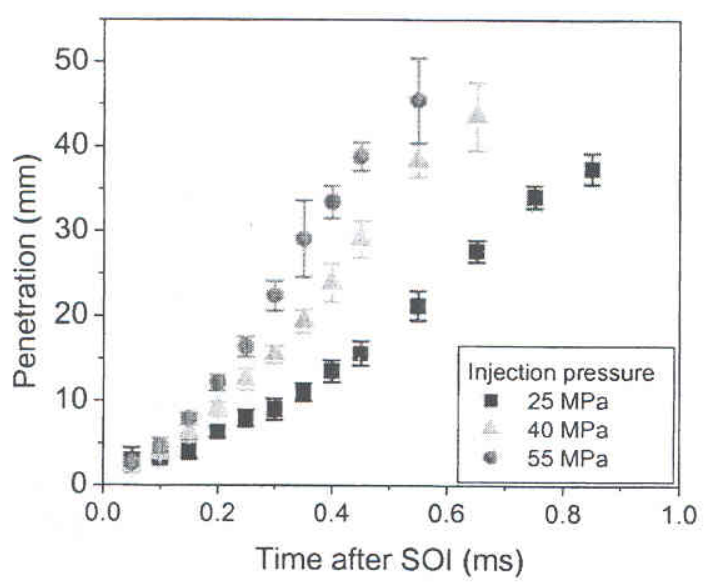

(a) Atmospheric chamber pressure

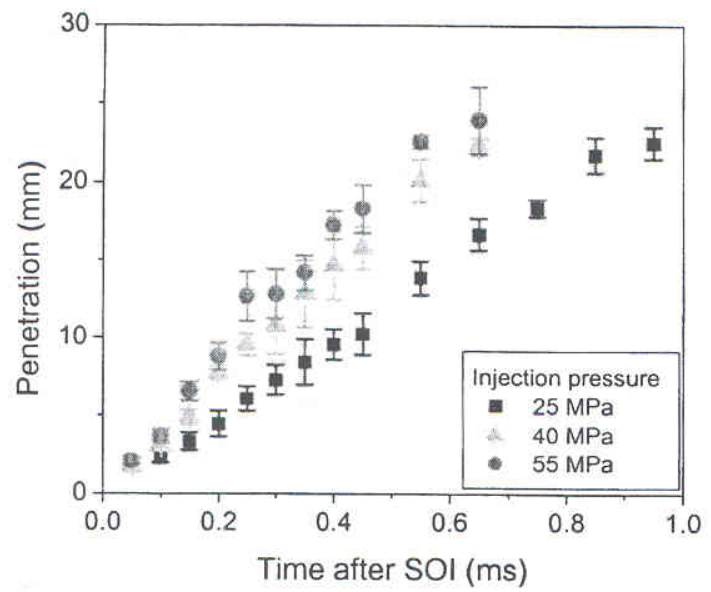

(b) $3 \mathrm{MPa}$ chamber pressure

Fig. 10 Effect of injection pressure on DME spray tip penetration

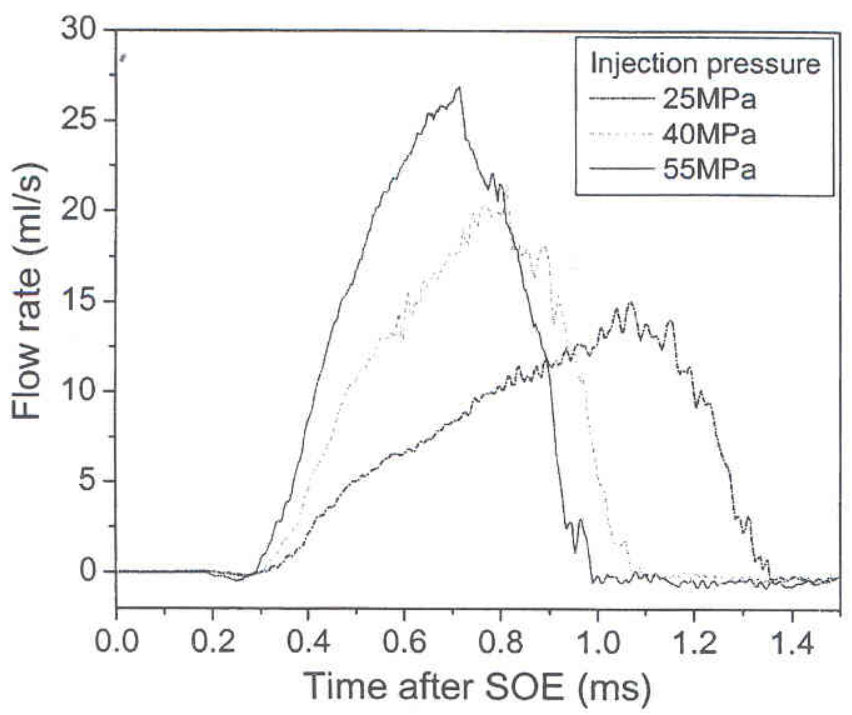

Fig. 11 DME injection rate, representing the amount of fuel from a nozzle hole, at different supply pressures under $3 \mathrm{MPa}$ pressure condition

D14502@ IMechE 2003 density inside the spray identical to the ambient density and with the injection rate increasing rapidly, resulting in a top-hat like shape of the injection rate curve. As previously studied with a similar injector [24], however, the fuel injection system employed in this study was unlikely to provide such a rapid injection rate, and the density of the spray might be far from that of the ambient condition. Hence, these models should overpredict the spray tip penetration with $\Delta P$ using a fixed commonrail pressure. The spray tip penetration models were applied by utilizing the instantaneous $\Delta P$ at each moment calculated from the transient injection rate.

Figure 12 compares experiments with the penetration model. It was found that Dent's model [equation (3)] resulted in best fit for the DME spray in this work, while $\Delta P$ in the equation adopts the calculated value from the measured injection rate profile in Fig. 11.

\subsection{Spray cone angle}

In general, the spray angle has been defined at $60 d_{\mathrm{o}}$ (hole diameter). However, for the DME spray injected under atmospheric chamber pressure, the $60 d_{\mathrm{o}}$ spray angle was not appropriate since the longitudinal spray dispersion was quite significant and the spray boundary had a smaller curvature so that two lines to define the spray angle cannot adequately follow the spray boundary [25]. Hence, in the present study, the spray cone angle was defined near the nozzle tip following the spray boundary from the nozzle. In the case of fuel injected under the $3 \mathrm{MPa}$ chamber pressure condition with $55 \mathrm{MPa}$ injection pressure, the spray cone angles of the DME were similar to those of diesel because of the reduced flash boiling effect, as shown in Fig. 13. Variation in the spray cone angles of each nozzle hole was relatively (approximately $0.65^{\circ}$ ) smaller than that for diesel because of the

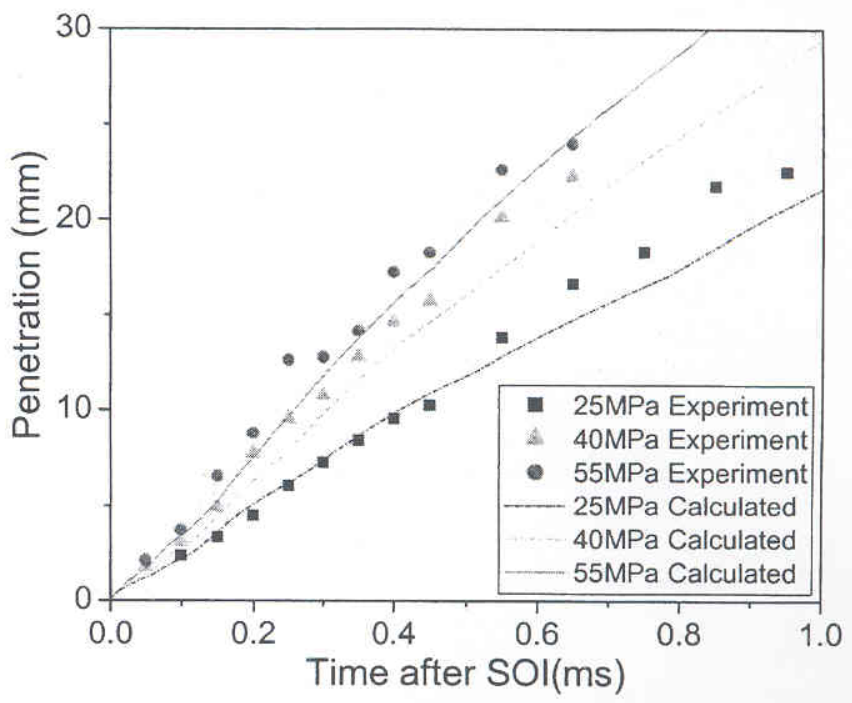

Fig. 12 Comparison of experiments with Dent's model at $3 \mathrm{MPa}$ chamber pressure

Proc. Instn Mech. Engrs Vol. 217 Part D: J. Automobile Engineering 

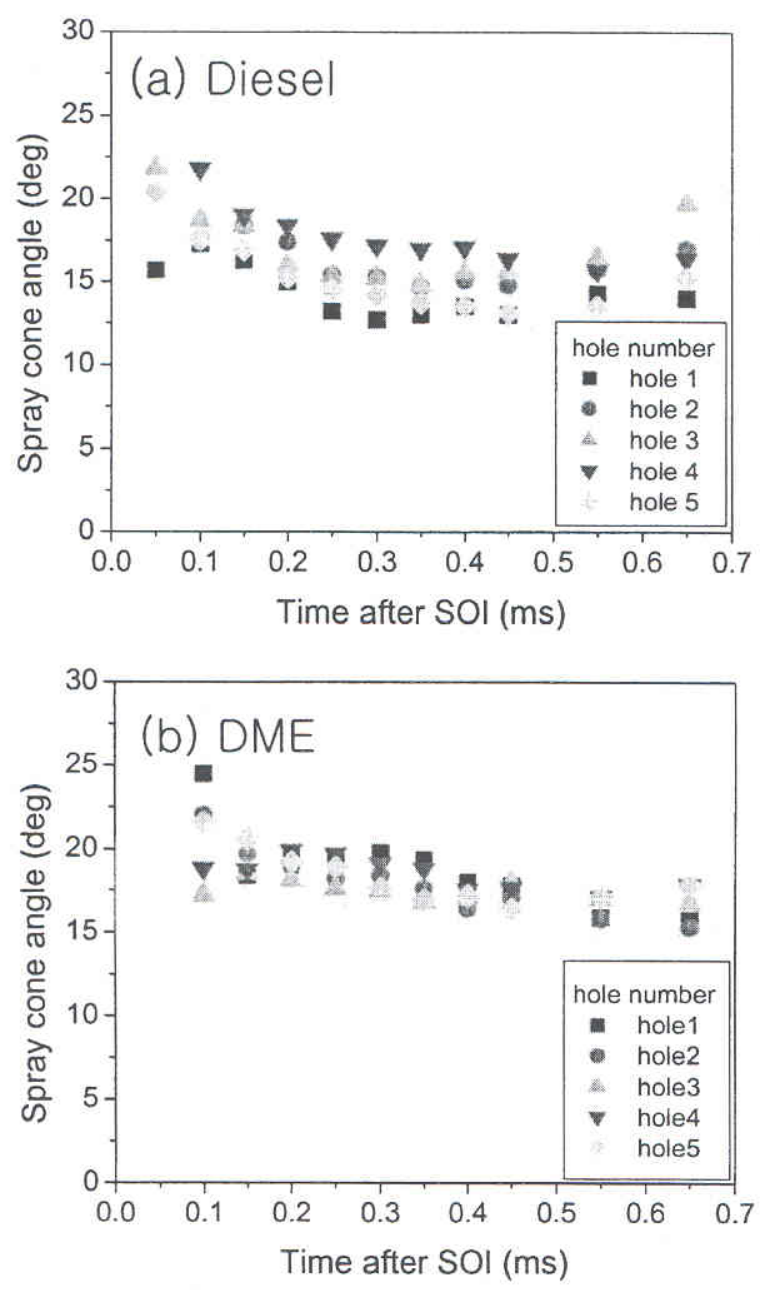

Fig. 13 Comparison of the spray cone angle of DME with diesel at $55 \mathrm{MPa}$ injection pressure and $3 \mathrm{MPa}$ chamber pressure

high compressibility of the DME. Figure 14 shows the effect of injection pressure on the DME spray cone angle. The spray angles were obtained by taking the mean value of the spray cone angles created from the five nozzle holes. In the case of the atmospheric chamber condition, the spray cone angle decreased with injection pressure, while its contribution was minimal in the case of $3 \mathrm{MPa}$ chamber pressure. In the case of DME spray atomized into the atmospheric chamber pressure condition, the spray cone angle was large owing to the flash boiling atomization. As the chamber pressure increased to $3 \mathrm{MPa}$, however, the spray cone angle was hardly affected by the flash boiling and eventually acquired a diesellike value (Fig. 14b).

\subsection{Evaporating spray characteristics}

Figure 15 are Mie scattered and shadowgraphic DME spray images taken with the nozzle holder for the singlehole spray. As can be seen from the shadowgraphic DME spray images (Figs $15 \mathrm{~b}$ and d), the vapour phase

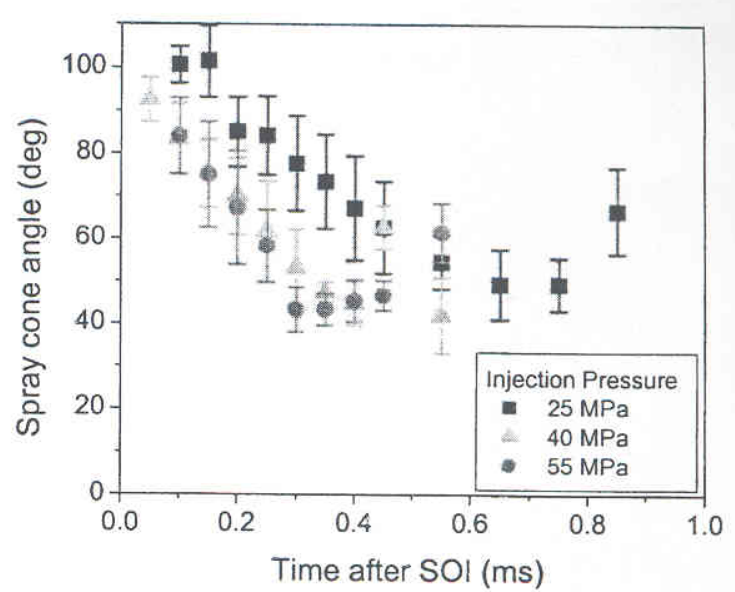

(a) atmospheric chamber pressure

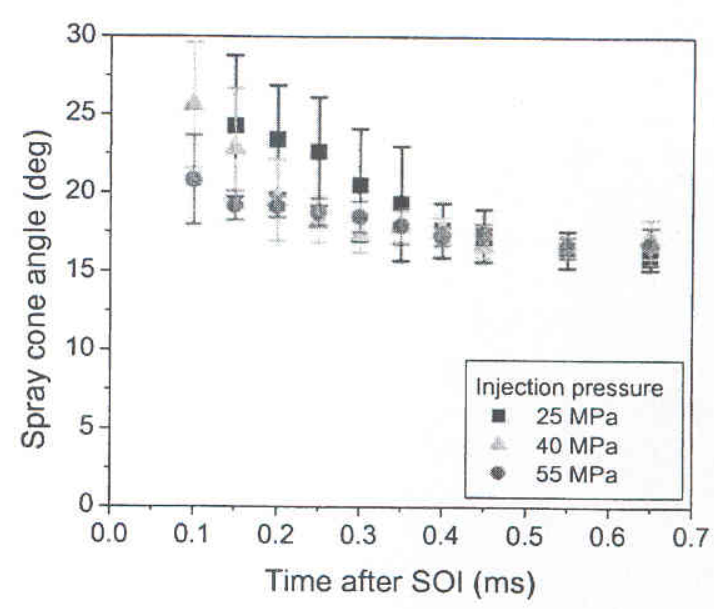

(b) 3 MPa chamber pressure

Fig. 14 Effect of injection pressure on DME spray cone angle at different chamber pressures
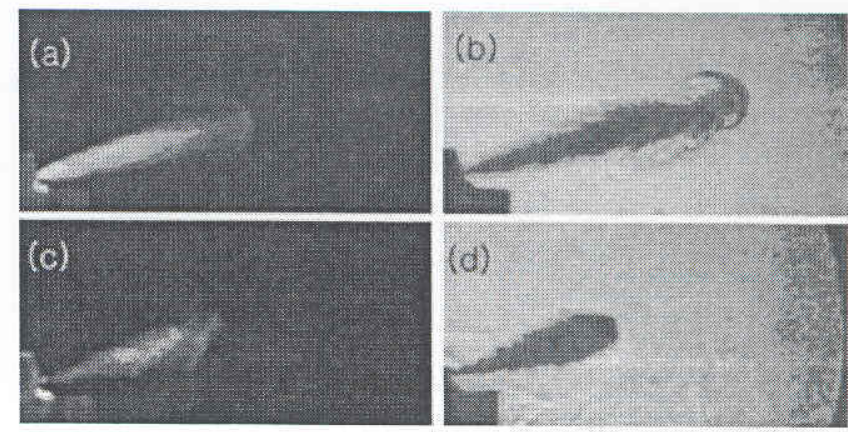

Fig. 15 Effect of chamber pressure on DME evaporation at different injection conditions: (a) $0.7 \mathrm{~ms}$ after SOI of Mie scattered spray at $25 \mathrm{MPa}$ injection pressure and atmospheric chamber pressure; (b) $0.7 \mathrm{~ms}$ after SOI of shadowgraphic spray at $25 \mathrm{MPa}$ injection pressure and atmospheric chamber pressure; (c) $0.6 \mathrm{~ms}$ after $\mathrm{SOI}$ of Mie scattered spray at $55 \mathrm{MPa}$ injection pressure and $3 \mathrm{MPa}$ chamber pressure; (d) $0.6 \mathrm{~ms}$ after SOI of shadowgraphic spray at $55 \mathrm{MPa}$ injection pressure and $3 \mathrm{MPa}$ chamber pressure 
of the DME was mainly generated in the region of the spray edge and downstream rather than upstream as the DME might be well atomized in the region of spray downstream and the edge, implying faster vaporization. This suggests that the droplet size of the spray in those regions was smaller, thereby resulting in greater ignitability $[26,27]$. The flash boiling effect can also provide better atomization and fuel/air mixing and reduce wall wetting by shortening spray tip penetration $[28,29]$. It can also be seen that, regardless of the injection pressure, the spray tip of the DME at atmospheric chamber pressure formed a mushroom-like shape, but this disappeared and became diesel like under $3 \mathrm{MPa}$ chamber pressure. Formation of the mushroom shape might be due to the fact that DME spray droplets abruptly evaporated as the highly pressurized DME was discharged into the atmospheric condition from the nozzle inside. Rapid momentum loss of each droplet and the shear stress created by interaction with ambient gas resulted in slower migration of the droplet and the generation of a vortex.

In this work, the evaporating characteristics of the spray were evaluated in terms of apparent vapour phase area obtained by subtraction of the Mie scattered image from the shadowgraphic spray image. Figure 16 shows the effect of injection pressure on DME evaporating characteristics at the different chamber pressures. As can be seen in Fig. 16a, at atmospheric chamber pressure, a $40 \mathrm{MPa}$ of injection pressure provided a wider vapour phase area than that produced by $25 \mathrm{MPa}$, but the contribution of further higher injection pressure (55 MPa) was minimal. For the case of $3 \mathrm{MPa}$ chamber pressure, the DME seemed still to be evaporated, though to a lesser extent than at atmospheric chamber pressure because of increased ambient resistance. This implies that the DME spray could provide better contact with the surrounding oxidant in an engine cylinder, but further investigations would be necessary in more realistic conditions considering the in-cylinder temperature effect. It may also imply that a higher injection pressure would provide faster and better atomization.

\section{CONCLUSIONS}

The study employing a common-rail type fuel injection system demonstrated the macroscopic spray characteristics of DME compared with those of diesel in a constant-volume chamber and the evaporating characteristics of the DME, allowing the following conclusions to be drawn:

1. Intrinsic spray characteristics of the DME appeared in atmospheric pressure conditions, characterized by the formation of mushroom-like shape of the spray tip and flash boiling, while it became diesel like with elevated ambient pressure conditions.

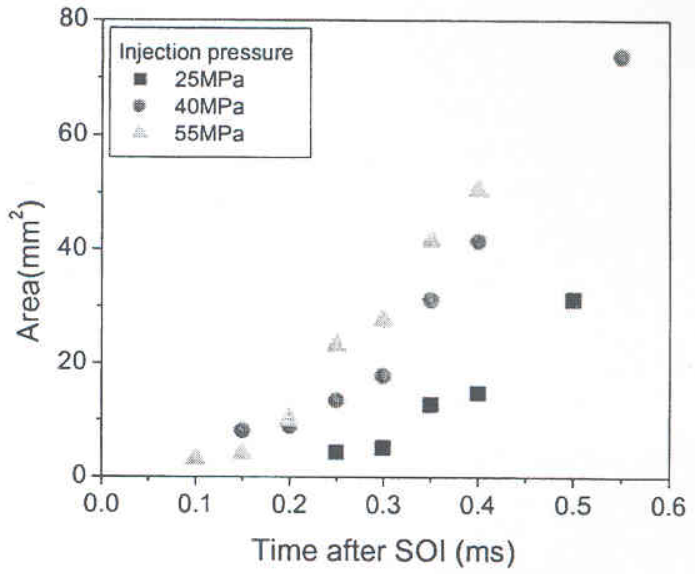

(a) Atmospheric chamber pressure

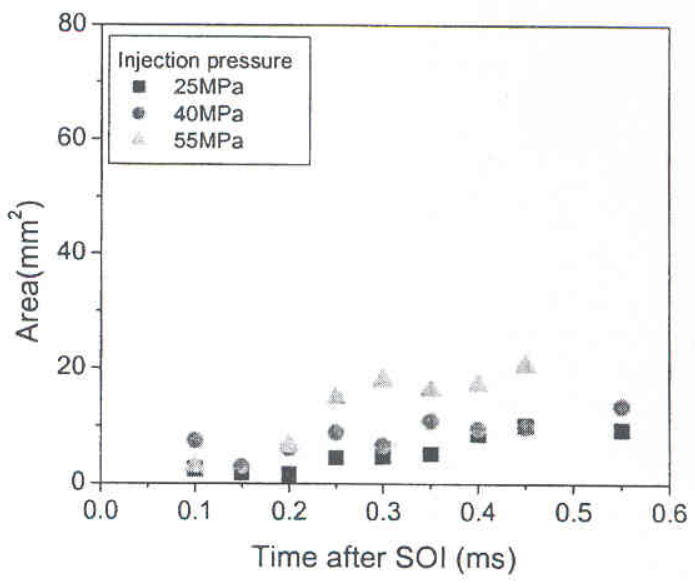

(b) $3 \mathrm{MPa}$ chamber pressure

Fig. 16 Apparent DME vapour phase area with different injection conditions

2. Unstable force balance on the ball valve inside the nozzle might lead to hesitating intermittent DME spray; the hesitating intermittent spray appeared to depend upon the injection pressure and high current holding time, representing the damping force and magnetic force respectively.

3. In atmospheric chamber pressure conditions, DME vapour was ejected before the discharging liquid, while only the liquid phase of DME was observed at $3 \mathrm{MPa}$ chamber pressure.

4. Vapour phase of DME spray was predominant in the region of the spray edge and downstream, suggesting greater ignitability there in the application of compression ignition engines.

5. The vaporizing region of the DME spray increased with injection pressure, regardless of the chamber pressure conditions, and DME was still evaporated at $3 \mathrm{MPa}$, though the area of the vapour phase decreased. Further investigations considering the temperature effect would be necessary.

Proc. Instn Mech. Engrs Vol. 217 Part D: J. Automobile Engineering 


\section{ACKNOWLEDGEMENTS}

This study was sponsored by the Combustion Engineering Research Centre in KAIST. The authors would like to thank Infineum Korea Limited for their donation of the DME lubricity additive Infineum R655.

\section{REFERENCES}

1 Verbeek, R. and Van der Weide, J. Global assessment of dimethyl ether comparison with other fuels. SAE paper 971607, 1997.

2 Sato, Y., Noda, A., Sakashi, T. and Goto, Y. Performance and emission characteristics of a DI diesel operated on dimethyl ether applying EGR with supercharging. SAE paper 2000-01-1809, 2000.

3 Christensen, R., Sorenson, S. C., Jensen, M. G. and Hansen, K. F. Engine operation on dimethyl ether in a naturally aspirated, DI diesel engine. SAE paper 971665 , 1997.

4 Sorensen, S.C. and Mikkelsen, S. Performance and emission of a 0.273 litre direct injection diesel engine fuelled with neat dimethyl ether. SAE paper 950064, 1995.

5 Kajitani, S., Oguma, M. and Mori, T. DME fuel blends for low-emission direct-injection diesel engines. SAE paper 2000-01-2004, 2000.

6 Kajitani, S., Chen, Z. L., Kono, M. and Rhee, K. T. Engine performance and exhaust characteristics of direct diesel engine operated with DME. SAE paper 972973, 1997.

7 Lonbao, Z., Hewu, W., Deming, J. and Zuohua, H. Study of performance and combustion characteristics of a DMEfuelled light-duty direct-injection diesel engine. SAE paper 1999-01-3669, 1999.

8 Sorenson, S. C., Glenvig, M. and Abata, D. L. Dimethyl ether in diesel fuel injection system. SAE paper 981159 , 1998.

9 Teng, H., McCandless, J. C. and Schneyer, J. B. Viscosity and lubricity of (liquid) dimethyl ether-an alternative fuel for compression-ignition engines. SAE paper 2002-010862, 2002.

10 Gill, D., Ofner, H., Sturman, E., Carpenter, J. and Wolverton. A. Production feasible DME technology for direct injection CI engines. SAE paper 2001-01-2015, 2001.

11 Anderson, O., Collin, R., Alden, M. and Egnell, R. Quantitative imaging of equivalence ratios in DME sprays using a chemically preheated combustion vessel. SAE paper 2000-01-2785, 2000.

12 Bosch, W. The fuel rate indicator; a new measuring instrument for displaying the characteristics of individual injection. SAE paper $660749,1966$.
13 Hiroyasu, H. and Arai, M. Structure of fuel sprays in diesel engines. SAE paper 900475, 1990.

14 Dent, J. C. A basis for the comparison of various experimental methods for studying spray penetration. SAE paper 710571, 1971.

15 Wakuri, Y., Fuji, M., Amitani, R. and Tsuneya, R. Studies on the penetration of fuel spray in a diesel engine. Bull. Jap. Soc. Mech. Engrs, 1960, 13, 9.

16 Schihl, P., Bryzik, W. and Atreys, A. Analysis of current spray penetration models and proposal of a phenomenological cone penetration model. SAE paper 960773, 1996.

17 Naber, J. D. and Siebers, D. Effects of gas density and vaporization on penetration and dispersion of diesel sprays. SAF paper 960034, 1996.

18 Wakai, K., Yoshizaki, T., Nishida, K., Hiroyasu, H. and Kawaguchi, Y. Numerical and experimental analyses of the injection characteristics of dimethyl ether with a D.I. diesel injection system. SAE paper 1999-01-1122, 1999.

19 Egnell, R. Comparison of heat release and NO $x$ formation in a DI diesel engine running on DME and diesel fuel. SAE paper 2001-01-0651, 2001.

20 Diesel-engine Management, 2nd edition, 1999 (Robert Bosch $\mathrm{GmbH}$ ).

21 Kennaird, D. A., Crua, C., Lacoste, J., Heikal, M. R., Gold, M. R. and Jackson, N. S. In-cylinder penetration and break-up of diesel sprays using a common-rail injection system. SAE paper 2002-01-1626, 2002.

22 Morgan, R., Wray, J., Kennaird, D. A., Crua, C. and Heikai, M. R. The influence of injector parameters on the formation and break-up of a diesel spray. SAE paper 2001-10-0529, 2001.

23 Lee, S. W., Kusakam, J. and Dashio, Y. Spray characteristics of alternative fuels in constant volume chamber (comparison of the spray characteristics of LPG, DME and n-dodecane). JSAE Rev., 2001, 22, 271.

24 Bae, C., Yu, J., Kong, J., Cuenca, R. and Lee, K. O. The influence of injector parameters on diesel spray. In Proceedings of THIESEL 2002 Conference on Thermo and Fluid Dynamic Processes in Diesel Engines, Valencia, 2002, pp. 55-66.

25 Yu, J., Lee, J. and Bae, C. Dimethyl ether (DME) spray characteristics compared to diesel in a common-rail fuel injection system. SAE paper 2002-01-2898, 2002.

26 Park, B. S. and Lee, S. Y. An experimental investigation of the flash atomization mechanism. Atomization and Spray, 1994, 4, 159.

27 Reitz, R. D. A photographic study of flash-boiling atomization, Aerosol Sci. and Technol., 1990, 12, 561.

28 Oza, R. D. On the mechanism of flashing injection of initially sub-cooled fuels. J. Fluids Engng, March 1984, 106, 105.

29 Zen, Y. and Lee, C. An atomization model for flash boiling sprays. Combust. Sci. and Technol., 2001, 169, 45. 